\title{
ELETROMOBILIDADE NO BRASIL: INICIATIVAS, OPORTUNIDADES E DESAFIOS
}

\author{
Erik Telles Pascoal ${ }^{1}$, Anderson Elias Furtado ${ }^{2}$ e Valter Silva Ferreira Filho ${ }^{3}$ \\ ${ }^{1}$ AEDB - Associação Educacional Dom Bosco. Faculdade de Engenharia de Resende \\ ${ }^{2}$ FARO - Faculdade de Roseira. Engenharia Mecânica \\ ${ }^{3}$ UNESP - Universidade Estadual Paulista Júlio de Mesquita Filho \\ E-mails: erik.pascoal@aedb.br, anderson.furtado@faroroseira.edu.br, \\ valterfilho8@yahoo.com.br
}

\section{RESUMO}

A mobilidade urbana encontra-se no centro de diversos debates da atualidade. Sobretudo aqueles referentes ao planejamento das grandes cidades, cujo sistema de transporte revela-se insuficiente às demandas sociais. Uma das principais iniciativas e aposta para tentar responder simultaneamente às dificuldades de mobilidade urbana nas grandes metrópoles e às preocupações com as questões ambientais é a eletromobilidade. Esta modalidade inclui os veículos elétricos puros, os veículos híbridos, os veículos movidos à célula de hidrogênio e os veículos alimentados por cabos externos. Apesar de suas vantagens, a implantação da eletromobilidade ainda não alcançou um patamar de destaque no Brasil. Fatores tecnológicos, legislação, subsídios e infraestrutura de uma rede de abastecimento são alguns dos obstáculos para a generalização dessa modalidade. Além disso, seu incentivo, por meio de políticas públicas nacionais para a mobilidade urbana ou mesmo iniciativas do setor privado, é ainda limitado ou inexistente. Neste contexto, o objetivo deste artigo é apresentar um panorama das principais iniciativas, oportunidades e desafios impostos ao desenvolvimento da eletromobilidade no cenário brasileiro.

\section{INTRODUÇÃO}

O transporte é um importante instrumento de direcionamento do desenvolvimento urbano das cidades. A mobilidade urbana bem planejada, com sistemas integrados, garante o acesso dos cidadãos às cidades e proporciona qualidade de vida e desenvolvimento econômico [1].

Atualmente, a mobilidade urbana é uma das prioridades da pauta de planejamento das cidades modernas. Os gestores públicos precisam enfrentar o desafio de apresentar soluções para o tráfego de 2,7 milhões de novos veículos que, a cada ano, passam a circular pelas vias urbanas do país, além da frota atual de aproximadamente 44 milhões [2].

Além disso, a mobilidade urbana é uma atividade transversal que envolve e afeta diversas áreas, como saúde, meio ambiente, educação, cidadania, urbanismo, acessibilidade e cultura [3]. Dada à sua complexidade, a gestão da mobilidade urbana demanda soluções inovadoras, o engajamento da população e o envolvimento de governo, empresas e a sociedade como um todo [3].

A mobilidade urbana torna-se, cada vez mais, um pré-requisito para o bem-estar social e o desenvolvimento econômico dos países, em especial os países emergentes mais carentes de infraestrutura [4]. 
No Brasil, a Lei 12.587/2012 estabelece os princípios, as diretrizes e os objetivos da Política Nacional de Mobilidade Urbana (PNMU), visando orientar a atuação tanto do Governo Federal quanto dos Estados e Municípios em busca de um padrão de mobilidade urbana. Os princípios da PNMU tratam de conceitos abrangentes que visam orientar a implantação da política dentre eles, destaca-se o desenvolvimento sustentável das cidades, nas dimensões socioeconômicas e ambientais. As diretrizes, por sua vez, são orientações sobre os caminhos que devem ser seguidos para se atingir os objetivos da Lei. Assim, dentre as diretrizes dispostas na PNMU, destaca-se a utilização de energias renováveis e menos poluentes nos sistemas de mobilidade. Já os objetivos definem a visão de futuro para o país. A partir do comprometimento dos governos e sociedade para a implementação desta política será possível, dentre outros, promover o desenvolvimento sustentável com a mitigação dos custos ambientais e socioeconômicos dos deslocamentos de pessoas e cargas nas cidades [1].

Observa-se que um tema bastante relevante envolvendo a mobilidade urbana é em relação à questão da sustentabilidade ambiental, em especial à dependência e consumo de combustíveis fósseis e a poluição atmosférica.

Do ponto de vista de consumo de petróleo e derivados, os transportes no mundo são responsáveis por mais de $60 \%$ deste consumo [5]. No Brasil, o consumo de petróleo e derivados, pelo setor de transportes, representa $66 \%$ do total, sendo que o modo rodoviário contribui com $92 \%$ deste gasto [6].

Do ponto de vista de emissões mundiais, o setor de transportes contribui com $24 \%$ das emissões de gases causadores do efeito estufa ou gases de efeito estufa (GEE) [5]. Considerando-se apenas o Brasil, aproximadamente $44 \%$ das emissões de $\mathrm{CO}_{2}$ tem origem nos transportes [5].

Não há uma solução única para as questões de mobilidade urbana, e sim um leque de alternativas. Dentre elas, este artigo propõe discutir a eletromobilidade. Em particular, esta modalidade se apresenta como uma das principais iniciativas e aposta para tentar responder simultaneamente às dificuldades de mobilidade urbana nas grandes metrópoles e às preocupações com as questões ambientais.

Neste contexto vários países da Europa já anunciaram as datas em que proibirão a venda de veículos movidos à combustão de derivados de petróleo: Noruega (2025), França (2030), Holanda (2035) e Reino Unido (2040) [7].

Apesar da evolução da eletromobilidade nesses países, ainda existem dúvidas, especialmente do ponto de vista social, em relação à mudança completa para esta modalidade. Há muitas discussões se a energia elétrica utilizada será realmente limpa, sobre o que ocorrerá em relação aos benefícios fiscais dos combustíveis fósseis e sobre a reciclagem e a extração de matérias primas para a fabricação de baterias [8]. Mesmo com esta dissonância, a eletromobilidade avança nos países desenvolvidos.

Entretanto, no Brasil, a implantação da eletromobilidade ainda não alcançou um patamar de destaque. Fatores tecnológicos, legislação, subsídios e infraestrutura de uma rede de abastecimento são alguns dos obstáculos para a generalização dessa modalidade. Além disso, seu incentivo, por meio de políticas públicas nacionais ainda é limitado ou inexistente.

O objetivo deste artigo é apresentar um panorama das principais iniciativas, oportunidades e desafios impostos ao desenvolvimento da eletromobilidade no cenário brasileiro.

O presente artigo está dividido nas seguintes seções além da introdução: na seção 1 é definida a eletromobilidade, na seção 2 são apresentadas as diferentes políticas públicas nacionais de incentivo a eletromobilidade, na seção 3 são listadas as principais instituições, projetos e empresas que têm apoiado a eletromobilidade no Brasil, a seção 4 tem como finalidade sintetizar os desafios e as oportunidades da eletromobilidade e, por fim, são apresentadas as conclusões deste artigo. 


\section{O QUE É A ELETROMOBILIDADE}

\subsection{Definição}

A mobilidade elétrica está relacionada à eletrificação do transporte, ou seja, visa possibilitar que as pessoas se locomovam utilizando veículos elétricos (VE) [9]. Desta forma, a eletromobilidade é entendida como meio de transporte (individual ou coletivo) com motores elétricos que usam diversas formas de abastecimento de energia. No geral, há uma ampla variedade de tipos de veículos elétricos disponíveis (por exemplo, scooters elétricas, carros elétricos, ônibus elétricos) [10].

Por utilizarem motores elétricos que substituem, total ou parcialmente, os motores de combustão interna, os VEs emitem menos GEE (Gases de Efeito Estufa ou simplesmente Gases Estufa), menos poluentes atmosféricos e apresentam menores níveis de ruído que os veículos tradicionais [9]. Sua aplicação é vista como uma contribuição para resolver tanto os desafios de transporte quanto os ambientais [10].

\subsection{Classificação}

Os VEs podem ser classificados em quatro principais famílias de acordo com a forma como a energia elétrica é disponibilizada a bordo [11]:

a) VE a bateria (VEB): são os veículos elétricos puros também denominados BEV (da sigla em inglês para Battery Electric Vehicles), cuja energia que alimenta o motor elétrico e propulsiona as rodas é fornecida por um conjunto de baterias que são recarregadas na rede elétrica. Como estes veículos usam exclusivamente a eletricidade como combustível, são considerados veículos all-electric.

b) VE híbrido (VEH): são aqueles que utilizam motores elétrico e à combustão interna para propulsão. Os VEHs são classificados como em série (quando utilizam apenas o motor elétrico para mover o carro, com o motor à combustão interna fornecendo eletricidade ao motor elétrico) ou paralelo (quando utilizam ambos os motores para propulsão). Os VEHs podem ser classificados em três tipos:

- Híbrido puro (HEV, da sigla em inglês Hibrid Electric Vehicle), cujo motor principal que propulsiona o veículo é à combustão interna. A função do motor elétrico é apenas melhorar a eficiência do motor à combustão interna ao fornecer tração em baixa potência.

- Híbrido plug-in (PHEV, da sigla em inglês Plug-in Hybrid Electric Vehicle), cujo motor à combustão interna também é o principal, mas eles podem, além disso, receber eletricidade diretamente de uma fonte externa.

- Híbrido de longo alcance (EREV, da sigla em inglês Extended Range Electric Vehicle), cujo motor principal é o elétrico - que é alimentado diretamente por uma fonte elétrica externa - com o motor à combustão interna fornecendo energia a um gerador, que mantém um nível mínimo de carga da bateria.

c) VE de célula a combustível (VECC): são veículos elétricos movidos por células de combustível também denominados FCEV (da sigla em inglês Fuel Cell Electric Vehicle), equipamento eletro-químico que combina hidrogênio e oxigênio para produzir a eletricidade que fará funcionar o motor.

d) VE ligado à rede ou trólebus: são veículos elétricos alimentados pela rede elétrica também denominados de RPEV (da sigla em inglês Road Powered Electric Vehicle). A energia é fornecida por meio de cabos externos diretamente conectados acima do veículo (com os trólebus) ou abaixo (como os veículos leves sobre trilhos - VLTs). 
No Quadro 1 encontram-se sintetizadas as principais informações sobre os diferentes tipos de VEs.

Quadro1: Principais características dos VEs

\begin{tabular}{|c|c|c|c|c|}
\hline $\begin{array}{l}\text { Tipo de } \\
\text { veículo }\end{array}$ & $\begin{array}{l}\text { VE a bateria } \\
\text { (VEB) }\end{array}$ & VE híbrido (VEH) & $\begin{array}{c}\text { VE de célula a } \\
\text { combustível (VECC) }\end{array}$ & $\begin{array}{c}\text { VE ligado à rede } \\
\text { ou trólebus }\end{array}$ \\
\hline $\begin{array}{l}\text { Tipo de } \\
\text { motor }\end{array}$ & $100 \%$ elétrico & $\begin{array}{l}\text { Motores à combustão } \\
\text { interna e elétrico dispostos } \\
\text { em paralelo. Motor à } \\
\text { combustão é o principal } \\
\text { para mover o veículo, com } \\
\text { auxílio de um pequeno } \\
\text { motor elétrico }\end{array}$ & $\begin{array}{l}\text { Sistema de célula de } \\
\text { combustível e motor } \\
\text { elétrico, que } \\
\text { propulsiona o } \\
\text { veículo, dispostos em } \\
\text { série. }\end{array}$ & $100 \%$ elétrico \\
\hline $\begin{array}{c}\text { Tipo de } \\
\text { combustível }\end{array}$ & Eletricidade & $\begin{array}{l}\text { Fóssil, biocombustível ou } \\
\text { eletricidade }\end{array}$ & Hidrogênio ou etanol & Eletricidade \\
\hline Autonomia & $\begin{array}{l}\text { Autonomia elétrica } \\
\text { de pequena a média } \\
\text { (comparada aos } \\
\text { veículos de } \\
\text { combustão interna) }\end{array}$ & $\begin{array}{l}\text { Pouca autonomia elétrica, } \\
\text { que é complementada pela } \\
\text { autonomia proporcionada } \\
\text { pelo combustível fóssil/ } \\
\text { biocombustível }\end{array}$ & $\begin{array}{l}\text { Autonomia elétrica } \\
\text { de média a alta }\end{array}$ & $\begin{array}{l}\text { Autonomia } \\
\text { elétrica alta }\end{array}$ \\
\hline Emissões & Zero & $0,062 \mathrm{~kg} \mathrm{CO} / \mathrm{km}$ & Zero & Zero \\
\hline $\begin{array}{l}\text { Exemplos } \\
\text { de veículos }\end{array}$ & $\begin{array}{l}\text { BMW i3, } \\
\text { Tesla S }\end{array}$ & $\begin{array}{l}\text { Toyota Prius, Lexus } \\
\text { CT200h, Ford Fusion } \\
\text { Hybrid, Mitsubishi } \\
\text { Outlander PHEV, } \\
\text { BMW i8, DS5 Hybrid4 e } \\
\text { 3008 Hybrid4 }\end{array}$ & $\begin{array}{l}\text { Nissan SOFC, Honda } \\
\text { FCX, Honda Clarity } \\
\text { Fuel Cell, Toyota } \\
\text { Mirai, Hyundai Nexo }\end{array}$ & Trólebus, VLT \\
\hline
\end{tabular}

\subsection{Frota de VEs no Brasil}

Em relação aos números de frota circulante no Brasil de VEs a bateria, VEs híbridos, VEs de célula a combustível e VEs ligado à rede, não existe uma consolidação de dados que contemple esta classificação da eletromobilidade. As informações existentes dizem respeito somente aos VEs a bateria e VEs híbridos.

De acordo com dados do Departamento Nacional de Trânsito (DENATRAN) existem cerca de 7.000 VEs a bateria e VEs híbridos em circulação hoje no Brasil. Desse total, mais da metade foram emplacados em 2016 (1.085 unidades) e 2017 (3.278 unidades), o que demonstra uma crescente importância deste segmento no país [12].

Apesar o aumento das vendas a lista de possibilidades para compra no Brasil de um carro elétrico ou híbrido ainda é relativamente restrita. Todos são veículos importados e ainda há modelos exclusivos para táxis [11]. No Quadro 2 estão relacionadas as opções disponíveis ao cliente brasileiro.

Quadro 2: VEs a bateria e VEs híbridos a venda no Brasil

\begin{tabular}{|c|c|}
\hline VEs a bateria & VEs híbridos \\
\hline Tesla Model 3 & Toyota Prius \\
\hline Tesla Model S & Ford Fusion Hybrid \\
\hline Chevrolet Bolt EV & BMW i3 \\
\hline Kandi Coco & Lexus CT 200h \\
\hline BYD E6 & BMW i8 \\
\hline Nissan Leaf (Disponível apenas para taxi) & Mitsubishi Outlander PHEV \\
\hline e-Golf e Golf GTE (Lançamento previsto em 2018) & Porshe Cayenne SE-Hybrid \\
\hline
\end{tabular}

Fonte: Adaptado [11]. 


\subsection{Frota de VEs no mundo}

Em relação a frota mundial de VEs a bateria e VEs híbridos, no início de 2018, a quantidade chegou a 3,2 milhões de veículos [13]. A previsão é que até 2020 chegue a 13 milhões e, em 2030, a 140 milhões, ou $10 \%$ da frota total de carros no mundo [14].

O carro mais vendido no mundo no primeiro trimestre de 2018 foi o Nissan Leaf, superando as 20.000 unidades. Se a mesma análise for por montadora, a líder foi a Tesla, com aproximadamente 30.000 veículos vendidos [15].

O número de vendas mundiais no primeiro trimestre desse ano foi de 305.000 carros $(59 \%$ de aumento em relação ao mesmo período do ano anterior). Essa situação torna a perspectiva de fechamento do ano de 2018 com comercialização de 2 milhões de unidades (representando $2 \%$ do mercado total de automóveis) uma previsão bastante realista [16].

\subsection{Normalização no Brasil}

As atividades de normalização da eletromobilidade no Brasil estão concentradas no Comitê Brasileiro de Eletricidade (ABNT/CB-003) por meio da Comissão de Estudos de Veículos Elétricos Rodoviários e Industriais (CE03:069.001) e no Comitê Brasileiro Automotivo (ABNT/CB-005) através da Comissão de Estudos de Veículos Propelidos a Eletricidade [17]. No Quadro 3 são apresentadas as principais normas publicadas pelos dois comitês.

Quadro 3: Normalização da eletromobilidade no Brasil

\begin{tabular}{|l|l|}
\hline \multicolumn{1}{|c|}{ Normas publicadas } & \multicolumn{1}{|c|}{ Tìtulo } \\
\hline ABNT NBR IEC 61434 & $\begin{array}{l}\text { Células e baterias secundárias contendo eletrólitos alcalino ou outro não-ácido } \\
- \text { Guia para designação da corrente em normas de células e baterias } \\
\text { secundárias alcalinas }\end{array}$ \\
\hline ABNT NBR IEC 62660-1 & $\begin{array}{l}\text { Células de lítio-íon secundárias para propulsão de veículos elétricos } \\
\text { rodoviários - Parte 1: Ensaio de desempenho }\end{array}$ \\
\hline ABNT NBR IEC 62660-2 & $\begin{array}{l}\text { Células de lítio-íon secundárias para propulsão de veículos elétricos } \\
\text { rodoviários - Parte 2: Ensaios de confiabilidade e abuso }\end{array}$ \\
\hline ABNT NBR IEC 61851-1 & $\begin{array}{l}\text { Sistema de recarga condutiva para veículos elétricos - Parte 1: Requisitos } \\
\text { gerais }\end{array}$ \\
\hline ABNT NBR IEC 61851-21 & $\begin{array}{l}\text { Sistema de recarga condutiva para veículos elétricos - Parte 21: Requisitos de } \\
\text { veículos elétricos para a conexão condutiva a uma alimentação em corrente } \\
\text { alternada ou contínua }\end{array}$ \\
\hline ABNT NBR IEC 61851-22 & $\begin{array}{l}\text { Sistema de recarga condutiva para veículos elétricos - Parte 22: Estação de } \\
\text { recarga em corrente alternada para veículos elétricos }\end{array}$ \\
\hline ABNT NBR IEC 62196-1 & $\begin{array}{l}\text { Plugues, tomadas, tomadas móveis para veículo elétrico e Plugues fixos de } \\
\text { veículos elétricos - Recarga condutiva para veículos elétricos - Parte 1: } \\
\text { Requisitos gerais }\end{array}$ \\
\hline ABNT NBR IEC 62196-2 & $\begin{array}{l}\text { Plugues, tomadas, tomadas móveis para veículo elétrico e plugues fixos de } \\
\text { veículo elétrico - Recarga condutiva para veículo elétrico - Parte 2: Requisitos } \\
\text { dimensionais de compatibilidade e de intercambiabilidade para os acessórios } \\
\text { em c.a. com pinos e contatos }\end{array}$ \\
\hline ABNT IEC/TR 60783 & Fiação e conectores dos veículos elétricos rodoviários \\
\hline ABNT NBR 16567 & $\begin{array}{l}\text { Veículos rodoviários propelidos a eletricidade - Vocabulário rodoviários híbridos elétricos leves - Medição de emissão de } \\
\text { escapamento e consumo de combustível e energia - Métodos de ensaio }\end{array}$ \\
\hline
\end{tabular}

Fonte: Adaptado [17]. 


\section{POLÍ́ticas E PROGRAMAS PÚBLICOS DE INCENTIVO A ELETROMOBILIDADE NO BRASIL}

Neste tópico são apresentados os principais instrumentos públicos e programas de incentivo ao desenvolvimento da eletromobilidade (em andamento ou já finalizados) no país.

\subsection{PAC Mobilidade}

O Programa de Aceleração do Crescimento (PAC) Mobilidade tem como objetivo combater às desigualdades sociais, transformando as cidades em espaços mais humanizados e priorizando o transporte coletivo urbano. No âmbito da eletromobilidade, o PAC Mobilidade tem fomentado projetos de grande e média capacidade como veículos leves sobre trilhos (VLT) e monotrilhos em diferentes regiões do país [18]. Na Figura 1 é apresentada uma correlação entre a quantidade de projetos do PAC Mobilidade e a quantidade de projetos relacionados apenas à eletromobilidade separados por estágio da obra.

Figura 1: Projetos do PAC Mobilidade versus Projetos de Eletromobilidade separados por estágio da obra

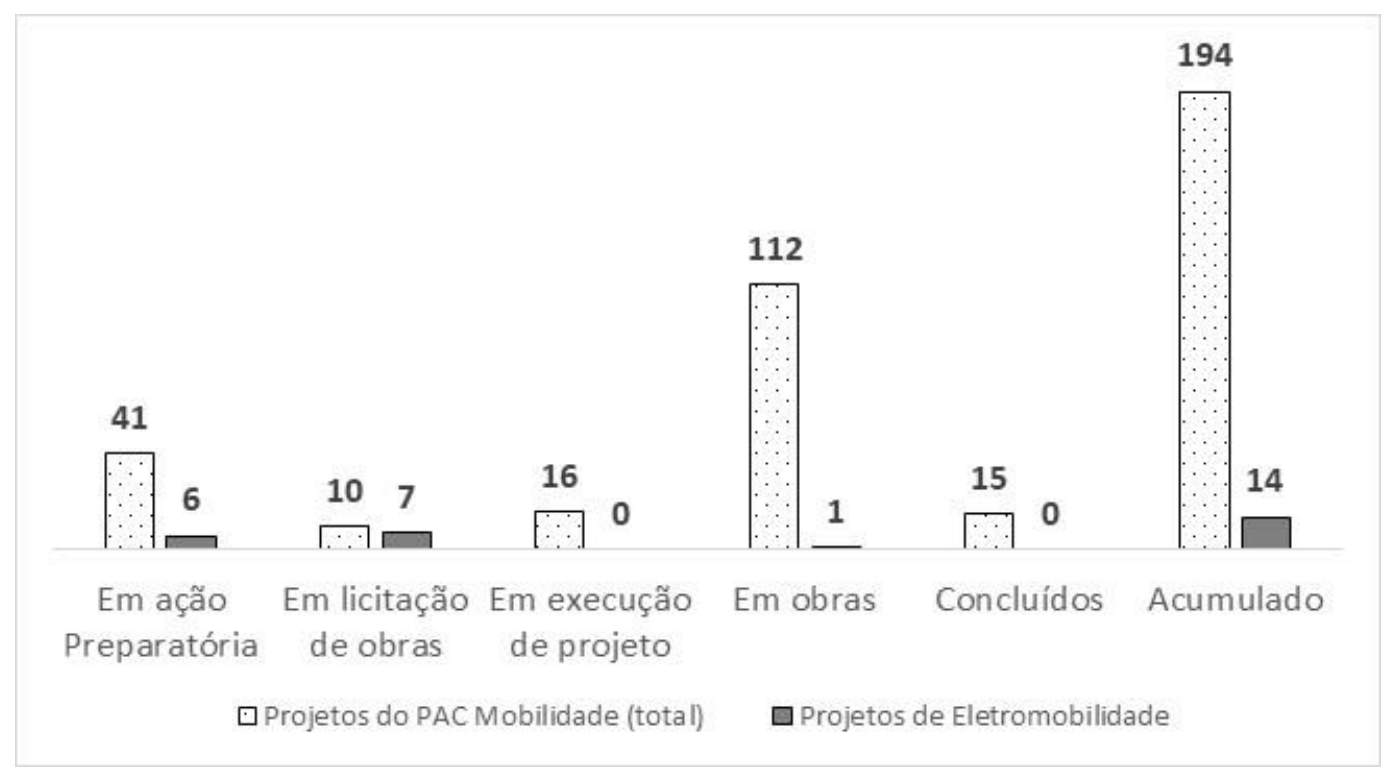

Fonte: [18].

No Quadro 4 são detalhados os projetos relacionados à eletromobilidade financiados pelo PAC Mobilidade separados por estágio da obra. 
Quadro 4: Projetos de eletromobilidade financiados pelo PAC Mobilidade

\begin{tabular}{|c|c|c|c|c|}
\hline $\begin{array}{l}\text { Estágio } \\
\text { da obra }\end{array}$ & Nome do Projeto & Estado & Cidade(s) & $\begin{array}{c}\text { Investimento previsto } \\
(\mathbf{R} \$)\end{array}$ \\
\hline \multirow{6}{*}{ 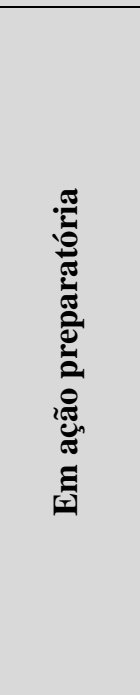 } & $\begin{array}{c}\text { EVTE do VLT Metropolitano - Trecho } \\
\text { Candeias - Mapele - Camaçari - Dias } \\
\text { D'ávila }\end{array}$ & $\mathrm{BA}$ & Salvador & Valor não divulgado \\
\hline & $\begin{array}{c}\text { Implantação de Sistema Integrado de } \\
\text { Transporte a partir de um Veículo Leve } \\
\text { sobre Trilhos }\end{array}$ & $\mathrm{PE}$ & Petrolina & Valor não divulgado \\
\hline & $\begin{array}{c}\text { Monotrilho - Metrô Linha } 3 \text { - São } \\
\text { Gonçalo-Niterói }\end{array}$ & RJ & São Gonçalo e Niterói & Valor não divulgado \\
\hline & $\begin{array}{c}\text { Monotrilho Linha } 18 \text { São Bernardo do } \\
\text { Campo/São Paulo - fase } 1 \text { - RM São } \\
\text { Paulo/SP }\end{array}$ & SP & $\begin{array}{l}\text { São Paulo, São } \\
\text { Bernardo do Campo, } \\
\text { Santo André e São } \\
\text { Caetano do Sul }\end{array}$ & Valor não divulgado \\
\hline & $\begin{array}{c}\text { Projeto do VLT - Centro de Maceió / } \\
\text { Aeroporto / Rio Largo }\end{array}$ & $\mathrm{AL}$ & Maceió & Valor não divulgado \\
\hline & $\begin{array}{c}\text { Projeto do VLT Metropolitano - Trechos } \\
\text { Retiro-Santa Luzia e Simões Filho-Águas } \\
\text { Claras }\end{array}$ & BA & Salvador & Valor não divulgado \\
\hline \multirow{7}{*}{ 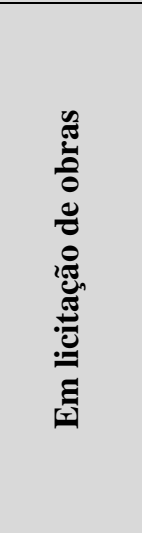 } & $\begin{array}{l}\text { Construção do Monotrilho Linha } 17 \text { - } \\
\text { Ouro - Trecho } 1\end{array}$ & SP & São Paulo & $2.582 .640 .000,00$ \\
\hline & $\begin{array}{l}\text { Implantação de linha de VLT Baixada } \\
\text { Santista }\end{array}$ & SP & Santos e São Vicente & $1.135 .830 .000,00$ \\
\hline & $\begin{array}{l}\text { Linha } 15 \text { - Prata do Metrô de São Paulo, } \\
\text { Implantação do Sistema Monotrilho, no } \\
\text { trecho entre as estações Vila Prudente } \\
\text { Hospital Cidade Tiradentes }\end{array}$ & $\mathrm{SP}$ & São Paulo & $4.585 .630 .000,00$ \\
\hline & $\begin{array}{l}\text { VLT - Rio de Janeiro/RJ - Área Central e } \\
\text { Portuária }\end{array}$ & RJ & Rio de Janeiro & $1.156 .680 .000,00$ \\
\hline & VLT Cuiabá / Várzea Grande & MT & Cuiabá & $1.577 .620 .000,00$ \\
\hline & VLT- Linha 1 - Sudeste & PI & Teresina & $444.000 .000,00$ \\
\hline & VLT: Parangaba / Mucuripe & $\mathrm{CE}$ & Fortaleza & $290.140 .000,00$ \\
\hline $\begin{array}{l}\text { Em } \\
\text { obras }\end{array}$ & $\begin{array}{l}\text { EVTE e Projetos do VLT Tancredo } \\
\text { Neves-Aeroporto }\end{array}$ & SP & Campinas & $1.500 .000,00$ \\
\hline
\end{tabular}

Fonte: Adaptado [18].

\subsection{Inova-Energia}

O Inova-Energia é uma iniciativa destinada à coordenação das ações de fomento à inovação e ao aprimoramento da integração dos instrumentos de apoio disponibilizados pela Financiadora de Estudos e Projetos (FINEP), pelo Banco Nacional de Desenvolvimento Econômico e Social (BNDES) e pela Agência Nacional de Energia Elétrica (ANEEL) que tem como uma de suas finalidades, no contexto da eletromobilidade, apoiar iniciativas que promovam o desenvolvimento de integradores e adensamento da cadeia de componentes na produção de veículos híbridos/elétricos no País [19], [20]. O fomento e a seleção de planos de negócio do Inova-Energia se destinará às seguintes cadeias produtivas:

a) Motores e sistemas de tração (Powertrains): desenvolvimento de tecnologias para motores, componentes e sistemas completos de tração elétrica para veículos automotores híbridos/elétricos, assim como tecnologias que possibilitem a melhoria da eficiência energética em sistemas de motorização a etanol (ou flex-fuel);

b) Baterias e acumuladores de energia: desenvolvimento de baterias, supercapacitores, outras tecnologias de acumuladores e recuperadores de energia para tração, pilhas a combustível e materiais para baterias, bem como sistemas de gerenciamento e seus 
componentes, para uso em veículos automotores híbridos/elétricos, preferencialmente a etanol;

c) Produção em escala: projetos pioneiros em escala piloto ou superior de desenvolvimento e implementação de produção de veículos automotores híbridos/elétricos, preferencialmente a etanol.

No Quadro 5 estão listadas as empresas aprovadas nesta área temática e o tipo de instrumento de apoio.

Quadro 5: Empresas participantes do Inova-Energia na área temática de veículos híbridos e eficiência energética veicular

\begin{tabular}{|c|c|c|c|c|c|c|}
\hline \multirow[t]{2}{*}{ Empresa Líder } & \multirow[t]{2}{*}{ Instituições participantes } & \multicolumn{5}{|c|}{$\begin{array}{l}\text { Instrumento de } \\
\text { Apoio }\end{array}$} \\
\hline & & 1 & 2 & 3 & 4 & 5 \\
\hline Acumuladores Moura S/A & Acumuladores Moura S/A & & & & & \\
\hline \multirow[t]{2}{*}{ Fiat Automóveis S/A } & Fiat Automóveis S/A & & & & & \\
\hline & Weg Equipamentos Elétricos S/A & & & & & \\
\hline Helicópteros do Brasil S/A & Universidade Federal de Itajubá & & & & & \\
\hline Hércules Motores Elétricos Ltda & Hércules Motores Elétricos Ltda & & & & & \\
\hline Johnson Controls PS do Brasil Ltda & Johnson Controls PS do Brasil Ltda & & & & & \\
\hline \multirow{2}{*}{$\begin{array}{l}\text { Magneti Marelli Sistemas Automotivos } \\
\text { Indústria e Comercio Ltda }\end{array}$} & $\begin{array}{l}\text { Fundação CPqD - Centro de Pesquisa e } \\
\text { Desenvolvimento em Telecomunicações }\end{array}$ & & & & & \\
\hline & $\begin{array}{l}\text { Magneti Marelli Sistemas Automotivos } \\
\text { Indústria e Comercio Ltda }\end{array}$ & & & & & \\
\hline Original Indústria Eletroeletrônica Ltda & Original Indústria Eletroeletrônica Ltda & & & & & \\
\hline Robert Bosch Ltda & Robert Bosch Ltda & & & & & \\
\hline \multirow{4}{*}{ Volvo do Brasil Veículos Ltda } & Universidade Federal de Santa Catarina & & & & & \\
\hline & Universidade Tecnológica Federal do Paraná & & & & & \\
\hline & Volvo do Brasil Veículos Ltda & & & & & \\
\hline & Weg Equipamentos Elétricos S/A & & & & & \\
\hline $\begin{array}{l}\text { Weg Drives \& Controls - Automação } \\
\text { Ltda }\end{array}$ & Weg Drives \& Controls - Automação Ltda & & & & & \\
\hline \multicolumn{7}{|c|}{$\begin{array}{l}1 \text { - Crédito } \\
2 \text { - Subvenção Econômica } \\
3 \text { - Cooperativo Instituições de Pesquisa Científica e Tecnológica (ICT) / empresa } \\
4 \text { - Programa de P\&D ANEEL } \\
5 \text { - BNDES Funtec }\end{array}$} \\
\hline
\end{tabular}

Fonte: Adaptado [19].

\subsection{BNDES Finem - Mobilidade Urbana}

É um programa que permite o financiamento a partir de $\mathrm{R} \$ 20$ milhões para projetos de investimentos de interesse público voltados à mobilidade urbana. Dentre eles, o financiamento para a aquisição de ônibus e caminhões híbridos, elétricos ou movidos a combustíveis limpos [21].

\subsection{Fundo Clima}

O Fundo Clima foi um subprograma de mobilidade urbana, encerrado no final de 2017, que teve como objetivo apoiar projetos que contribuíssem para a redução da emissão de gases do efeito estufa e de poluentes locais no transporte coletivo urbano de passageiros e para a melhoria da mobilidade urbana localizados nas regiões metropolitanas. Dentre os empreendimentos apoiáveis, no contexto da eletromobilidade, destaca-se a capacidade 
produtiva para a fabricação de ônibus elétricos, híbridos ou outros modelos com tração elétrica e material rodante para transporte urbano de passageiros sobre trilhos [22].

\subsection{Inovar-Auto}

O Programa de Incentivo à Inovação Tecnológica e Adensamento da Cadeia Produtiva de Veículos Automotores, denominado de Inovar-Auto, iniciado em 2013 e finalizado em dezembro de 2017, buscou estimular a concorrência e a busca de ganhos sistêmicos de eficiência e aumento de produtividade da cadeia automotiva. Do ponto de vista de incentivo fiscal à eletromobilidade, somente a partir do segundo semestre de 2014 o programa InovarAuto passou a contemplar os modelos de veículos elétricos híbridos (VEH). As demais configurações e modelos de veículos elétricos, como o VE a bateria (VEB), 100\% elétrico, não foram incluídas do programa [20].

2.6 Rota 2030

A nova política industrial para o setor automotivo, denominada de Rota2030, que se encontra ainda em discussão propõe ações para a eletromobilidade entre elas [23]:

- Atração de investimentos ao país, incluindo a montagem de veículos híbridos e elétricos e seus componentes;

- Criação de um grupo de trabalho focado em veículos híbridos e elétricos com vistas a elaboração de um Plano Nacional para Desenvolvimento da Eletromobilidade no Brasil.

\subsection{Isenções fisscais do poder público estadual}

As iniciativas referem-se à isenção do Imposto sobre a Propriedade de Veículos Automotores (IPVA) para proprietários de veículos elétricos nos estados do Ceará, Maranhão, Pernambuco, Piauí, Sergipe, Rio Grande do Norte e Rio Grande do Sul; e propostas de alíquotas diferenciadas para os proprietários dos veículos elétricos nos estados do Rio Janeiro, São Paulo e Mato Grosso do Sul [20].

\subsection{Lei Ambiental No 16.802/2018 (Prefeitura de São Paulo)}

A Lei Municipal No 16.802/2018, sancionada em 17 de janeiro de 2018 pela Prefeitura de São Paulo especifica cronogramas anuais com as metas de corte de poluentes que serão exigidas pelos concessionários ao longo de 20 anos. Essas metas levarão à troca da maior parte da atual frota de ônibus a diesel (14.400 unidades) por ônibus elétricos e híbridos, ou movidos a outras tecnologias de energia renovável [24].

\section{PRINCIPAIS INSTITUIÇÕES, PROJETOS E EMPRESAS DE APOIO A ELETROMOBILIDADE NO BRASIL}

Nesta seção são listadas as principais instituições públicas e privadas, projetos em andamento ou já finalizados e empresas que tem contribuído para o desenvolvimento da eletromobilidade no país sumarizadas no Quadro 6. 
Quadro 6: Instituições, Projetos e Empresas de Apoio a eletromobilidade no Brasil

\begin{tabular}{|c|c|}
\hline 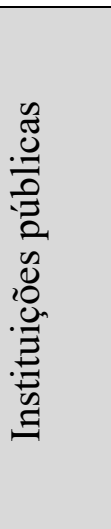 & $\begin{array}{l}\text { - } \text { Ministério do Desenvolvimento, Indústria e Comércio Exterior (MDIC), } \\
\text { - } \quad \text { Ministério das Cidades, } \\
\text { - } \quad \text { Agecretaria Nacional de Mobilidade Urbana (SEMOB), } \\
\text { - } \text { ITAIPU (Centro de Inovação em Mobilidade Elétrica Sustentável e o Centro de } \\
\text { Pesquisa, Desenvolvimento e Montagem de Veículos Elétricos), } \\
\text { - } \quad \text { Ganco Nacional de Desenvolvimento Econômico e Social (BNDES) } \\
\text { - } \quad \text { Grupo de Estudos de Setor Elétrico (GESEL) da UFRJ, } \\
\text { - } \quad \text { Laboratório de Estudos do do Veículo Elétricos (GRUVE) da UERJ, } \\
\text { Le de Veículos Elétricos (da UnB). }\end{array}$ \\
\hline 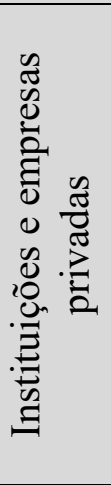 & $\begin{array}{l}\text { - } \text { Associação Brasileira do Veículo Elétrico (ABVE), } \\
\text { - Instituto Nacional de Eficiência Energética (INEE), } \\
\text { - } \quad \text { Centro de pesquisa em mobilidade elétrica (da ENEL), } \\
\text { - } \text { FGV Energia, } \\
\text { - SAE Brasil (Comissão Veículos Elétricos \& Híbridos) } \\
\text { - } \quad \text { Serttel, } \\
\text { - } \quad \text { Eletra, } \\
\text { - } \quad \text { BYD, } \\
\text { - } \quad \text { Renault/Nissan. }\end{array}$ \\
\hline & $\begin{array}{l}\text { - Projeto Emotive (da CPFL), } \\
\text { - PROMOB-e (Cooperação MDIC/Alemanha), } \\
\text { - } \text { Elétrica (da ANEEL), } \\
\text { - } \text { Projeto Veículo Elétrico (da ITAIPU) } \\
\text { - Projeto Ônibus Elétrico (da Universidade Federal de Santa Catarina), } \\
\text { - Projeto Faísca e Projeto Venturo (da Escola de Engenharia de São Carlos), } \\
\text { - Projeto Porto Leve em Recife/PE, } \\
\text { - Projeto Sivi (Sistema Veicular Inteligente) da UFGRS, } \\
\text { - Projetos de táxis elétricos no RJ e SP (já finalizado). }\end{array}$ \\
\hline
\end{tabular}

Fonte: [25], [26], [27], [28], [29], [30], [31], [32], [33], [34], [35], [36], [37], [38], [39], [40], [41], [42], [43], [44], [45], [46], [47], [48], [49], [50], [51], [52], [53], [54].

Dentre os projetos em andamento, destaca-se o Programa de Pesquisa e Desenvolvimento Tecnológico do Setor de Energia Elétrica da ANEEL. O objetivo do Programa de P\&D é alocar adequadamente recursos humanos e financeiros em projetos que demonstrem a originalidade, aplicabilidade, relevância e a viabilidade econômica de produtos e serviços, nos processos e usos finais de energia [55]. No Quadro 7 estão listados os projetos relacionados com o tema da eletromobilidade financiados pelo Programa de P\&D. 
Quadro 7: Projetos de Mobilidade Elétrica financiados pelo Programa de P\&D da ANEEL

\begin{tabular}{|c|c|}
\hline Empresa & Título do Projeto \\
\hline CPFL - Paulista & $\begin{array}{l}\text { Mobilidade Elétrica - inserção técnica e comercial de veículos elétricos em frotas } \\
\text { empresariais da Região Metropolitana de Campinas/SP }\end{array}$ \\
\hline CPFL - Paulista & $\begin{array}{l}\text { Desenvolvimento de um sistema de motorização auxiliar modular e regenerativos } \\
\text { para veículos }\end{array}$ \\
\hline Light Energia & $\begin{array}{l}\text { Metodologia de planejamento e análise para a implantação de veículos elétricos em } \\
\text { atividade de transportes }\end{array}$ \\
\hline Light Energia & $\begin{array}{l}\text { Desenvolvimento de um sistema inteligente de gestão de fontes renováveis, } \\
\text { armazenamento distribuído e veículos elétricos recarregáveis integrados ao conceito e } \\
\text { plataforma Smart Grid }\end{array}$ \\
\hline Petrobrás & Sistema de abastecimento de veículos com hidrogênio gerado a partir de eletricidade \\
\hline $\begin{array}{l}\text { Elektro } \\
\text { Distribuidora de } \\
\text { Energia }\end{array}$ & $\begin{array}{l}\text { Desenvolvimento de um sistema de propulsão para veículos elétricos de transporte de } \\
\text { passageiros sem uso de rede aérea para recarga }\end{array}$ \\
\hline $\begin{array}{l}\text { Elektro } \\
\text { Distribuidora de } \\
\text { Energia }\end{array}$ & $\begin{array}{l}\text { Desenvolvimento de um sistema de propulsão para veículos elétricos de transporte de } \\
\text { passageiros sem uso de rede aérea para recarga }\end{array}$ \\
\hline EDP - Bandeirantes & $\begin{array}{l}\text { Avaliação dos possíveis cenários, experimentação e mensuração dos impactos dos } \\
\text { veículos elétricos nos sistemas de distribuição da Bandeirante e da Escelsa }\end{array}$ \\
\hline $\begin{array}{l}\text { Companhia } \\
\text { Energética de Minas } \\
\text { Gerais - Cemig }\end{array}$ & $\begin{array}{l}\text { Desenvolvimento de Metodologia Para Análise dos Impactos da Integração de } \\
\text { Veículo Elétricos à Rede de Distribuição }\end{array}$ \\
\hline CEB - Distribuição & $\begin{array}{l}\text { Eletroposto Solar - Microgeração fotovoltaica distribuída integrada à arquitetura } \\
\text { predial e sua aplicação para carregamento de veículos elétricos }\end{array}$ \\
\hline CEB - Distribuição & $\begin{array}{l}\text { Metodologia, projeto demonstrativo e ferramenta computacional para a avaliação e } \\
\text { gestão operacional de arranjos técnicos e comerciais de inserção de veículo elétrico } \\
\text { no sistema de distribuição da CEB }\end{array}$ \\
\hline $\begin{array}{l}\text { CELESC - } \\
\text { Distribuição }\end{array}$ & $\begin{array}{l}\text { Sistema de Recarga Rápida com Armazenamento Híbrido-Estacionário de Energia } \\
\text { para Abastecimento de Veículos Elétricos no Conceito de Redes Inteligentes }\end{array}$ \\
\hline ENEL & $\begin{array}{l}\text { Desenvolvimento de Sistema de Gestão de Recarga para Veículos Elétricos em } \\
\text { Regime de Car Sharing }\end{array}$ \\
\hline ENEL & $\begin{array}{l}\text { Desenvolvimento de Sistema de Gestão de Recarga para Veículos Elétricos em } \\
\text { Regime de Car Sharing }\end{array}$ \\
\hline FURNAS & Desenvolvimento e Testes de Ônibus Urbanos com Tração Elétrica \\
\hline FURNAS & Desenvolvimento e Testes de Embarcação com Tração Elétrica \\
\hline
\end{tabular}

Fonte: [55].

\section{DESAFIOS E OPORTUNIDADES}

Existe um certo consenso na literatura a respeito dos desafios e oportunidades impostas ao desenvolvimento da eletromobilidade no Brasil. Neste contexto, os VEs ligados à rede, como os veículos leves sobre trilhos e trólebus, são considerados uma tecnologia madura na qual eventuais inovações terão caráter incremental e não a emersão de novas tecnologias. Em contrapartida, no transporte rodoviário, a inserção de VEs, principalmente com alimentação externa de energia, representa uma importante alteração do modelo tecnológico vigente [56]. Os Quadros 8 e 9 sintetizam os principais desafios e oportunidades a serem enfrentados pelos VEs com alimentação externa conforme apontam diferentes fontes pesquisadas. 
Quadro 8: Principais desafios

\begin{tabular}{|c|c|c|}
\hline Descrição & Comentários & Fonte \\
\hline $\begin{array}{l}\text { Desenvolvimento de } \\
\text { infraestrutura pública } \\
\text { para recarga }\end{array}$ & $\begin{array}{l}\text { É necessária uma rede de infraestrutura de recarga (eletropostos) } \\
\text { acessível para propiciar a adoção desta nova tecnologia pelo } \\
\text { consumidor }\end{array}$ & $\begin{array}{l}{[20]} \\
{[23]} \\
{[57]} \\
{[61]}\end{array}$ \\
\hline Autonomia das baterias & $\begin{array}{l}\text { Deve-se avançar os estudos para aumentar a autonomia entre } \\
\text { uma carga e outra da bateria dos VEs }\end{array}$ & [11] \\
\hline $\begin{array}{l}\text { Reciclagem das baterias } \\
\text { no final de vida }\end{array}$ & $\begin{array}{l}\text { Um importante risco ambiental dos VEs está associado à bateria, } \\
\text { que deve ser reciclada ao final de sua vida útil }\end{array}$ & $\begin{array}{l}{[58]} \\
{[61]}\end{array}$ \\
\hline $\begin{array}{l}\text { Capacitação técnica } \\
\text { para a nova indústria e } \\
\text { rede de serviços }\end{array}$ & $\begin{array}{l}\text { E necessário a formação/qualificação de mão de obra específica } \\
\text { para trabalhar nesta nova tecnologia e seus serviços associados }\end{array}$ & {$[23]$} \\
\hline Padrões e protocolos & $\begin{array}{l}\text { As montadoras inventaram diferentes padrões de plugue para a } \\
\text { tomada de energia de seus VEs. É preciso limitar o número de } \\
\text { formatos de plugue utilizados para que os custos se mantenham } \\
\text { num patamar razoável }\end{array}$ & {$[11]$} \\
\hline $\begin{array}{l}\text { Governança da } \\
\text { eletromobilidade }\end{array}$ & $\begin{array}{l}\text { Em razão da multiplicidade de atores torna-se necessário uma } \\
\text { coordenação intergovernamental }\end{array}$ & [23] \\
\hline $\begin{array}{l}\text { Regulamentação do } \\
\text { setor }\end{array}$ & $\begin{array}{l}\text { A legislação e a regulação se fazem necessárias para a } \\
\text { viabilidade dos investimentos. } \\
\text { Adoção de tarifas diferenciadas, de forma a incentivar o } \\
\text { carregamento das baterias fora do horário de ponta e, assim } \\
\text { evitar impactos nos sistemas de distribuição }\end{array}$ & $\begin{array}{l}20] \\
{[23]} \\
{[61]}\end{array}$ \\
\hline $\begin{array}{l}\text { Adaptação das cadeias } \\
\text { industriais }\end{array}$ & $\begin{array}{l}\text { É de extrema importância a adaptação gradativa das cadeias } \\
\text { industriais no processo de eletromobilidade }\end{array}$ & {$[57]$} \\
\hline $\begin{array}{l}\text { Conflito entre políticas } \\
\text { públicas }\end{array}$ & $\begin{array}{l}\text { Deve haver uma sinergia entre as iniciativas públicas nas três } \\
\text { esferas: Federal, Estadual e Municipal. }\end{array}$ & [57] \\
\hline Financiamento & $\begin{array}{l}\text { O financiamento privado poderia ser viabilizado por meio de } \\
\text { parcerias público-privadas (PPPs), por exemplo }\end{array}$ & $\begin{array}{l}{[59]} \\
{[60]}\end{array}$ \\
\hline Modelos de negócios & $\begin{array}{l}\text { É necessário que os novos modelos de negócios atraiam novas } \\
\text { tecnologias e P\&D para o país e também crie novas } \\
\text { oportunidades de emprego }\end{array}$ & $\begin{array}{l}{[57]} \\
{[61]}\end{array}$ \\
\hline $\begin{array}{l}\text { Gerenciamento dos } \\
\text { riscos }\end{array}$ & $\begin{array}{l}\text { Incerteza quanto ao atingimento da competitividade dos VEs em } \\
\text { relação aos modelos de combustão interna }\end{array}$ & {$[57]$} \\
\hline $\begin{array}{l}\text { Custo de aquisição dos } \\
\text { VEs }\end{array}$ & $\begin{array}{l}\text { O modelo mais barato a venda no país custa em média } \\
\mathrm{R} \$ 120.000,00 .\end{array}$ & $\begin{array}{l}{[11]} \\
{[57]} \\
{[61]}\end{array}$ \\
\hline
\end{tabular}


Quadro 9: Principais oportunidades

\begin{tabular}{|c|c|c|}
\hline Descrição & Comentários & Fonte \\
\hline Matriz energética & Utilização de uma matriz energética predominantemente limpa & {$[23]$} \\
\hline Investimentos & $\begin{array}{l}\text { Possibilidade de atração de novos investimentos ao país, } \\
\text { incluindo a montagem de veículos híbridos e elétricos e seus } \\
\text { componentes, viabilizados por meio de políticas públicas como o } \\
\text { ROTA2030 }\end{array}$ & {$[23]$} \\
\hline P\&D e inovação & $\begin{array}{l}\text { Perspectiva de fomento a P\&D e Inovação no país e } \\
\text { desenvolvimento de novas tecnologias de propulsão (ex: célula a } \\
\text { combustível de etanol) e novas tecnologias para acumuladores } \\
\text { (ex: Grafeno e Sódio) }\end{array}$ & [23] \\
\hline $\begin{array}{l}\text { Redução emissões e } \\
\text { ruídos }\end{array}$ & $\begin{array}{l}\text { Grande potencial de redução de emissões e ruídos nas grandes } \\
\text { cidades, convertendo-se em ganhos econômicos relativos à saúde } \\
\text { pública }\end{array}$ & {$[23]$} \\
\hline Empregos & $\begin{array}{l}\text { Grande oportunidade para a criação de novos empregos no país } \\
\text { motivados pelos novos modelos de negócios (ex: carsharing). }\end{array}$ & $\begin{array}{l}{[11]} \\
{[20]}\end{array}$ \\
\hline Novos negócios & $\begin{array}{l}\text { Desenvolvimento de novos negócios relacionados } \\
\text { principalmente à infraestrutura de recarga (ex: desenvolvimento, } \\
\text { produção, vendas, instalação e operação das estações de recarga) } \\
\text { e reciclagem das baterias e gerenciamento de sistemas/dados (ex: } \\
\text { gerenciamento de pagamentos, serviços de informação) }\end{array}$ & $\begin{array}{l}{[11]} \\
{[20]}\end{array}$ \\
\hline $\begin{array}{l}\text { Veículo para Rede } \\
\text { (V2G) e } \\
\text { Veículo para Casa } \\
\text { (V2H) }\end{array}$ & $\begin{array}{l}\text { No longo prazo, a inserção em larga escala de veículos elétricos, } \\
\text { associada à difusão de redes inteligentes, cria possibilidade para } \\
\text { que os veículos possam deixar de ser meros consumidores de } \\
\text { energia e passem a também ser ofertantes. Este sistema é } \\
\text { denominado vehicle to grid (V2G) e vehicle to home (V2H) pode } \\
\text { contribuir de forma relevante para a inserção em larga escala de } \\
\text { fontes renováveis e intermitentes na matriz elétrica }\end{array}$ & $\begin{array}{l}{[11]} \\
{[58]}\end{array}$ \\
\hline
\end{tabular}

\section{CONCLUSÃO}

Apesar dos desafios de ordem tecnológicos, regulamentares, infraestrutura e econômicos a serem superados é indiscutível a contribuição que a eletromobilidade oferece e que poderá ser ainda mais ampliada para a melhoria da mobilidade urbana nas grandes cidades do país. Porém é importante ressaltar que a eletromobilidade possui dois espectros muito relevantes para a questão da mobilidade urbana. Ela possui uma capacidade de atender tanto o modal rodoviário (transporte individual) quanto o modal de transporte coletivo urbano. As informações sobre estes dois espectros da eletromobilidade no cenário nacional estão consolidadas no Quadro 10, elaborado a partir das informações constantes neste artigo. 
Quadro 10: Os espectros da eletromobilidade

\begin{tabular}{|c|c|c|c|}
\hline Item & Modal rodoviário & $\begin{array}{l}\text { Modal de transporte } \\
\text { coletivo urbano }\end{array}$ & Seção \\
\hline Tipo principal de usuário & Individual/familiar & Coletivo & 1 \\
\hline Tipo de VEs & VEB, VEH e VECC & Trólebus, VLT & 1 \\
\hline Frota nacional & $\begin{array}{l}\text { - } \quad \text { VEB, VEH: cerca de } \\
7.000 \text { veículos, } \\
\text { - VECC (dados não } \\
\text { disponíveis) }\end{array}$ & Dados não disponíveis & 1 \\
\hline Incentivos públicos & $\begin{array}{ll}\text { - } & \text { Inovar-Auto, } \\
\text { - } & \text { Rota2030, } \\
\text { - } & \text { Inova-Energia, } \\
\text { - } & \text { Isenções fiscais } \\
& \text { estaduais }\end{array}$ & $\begin{array}{ll}\text { - } & \text { PAC Mobilidade, } \\
\text { - } & \text { BNDES Finem - } \\
& \text { Mobilidade Urbana, } \\
\text { - } & \text { Fundo Clima } \\
\text { - Lei Municipal São Paulo } & \\
& \left(\mathrm{N}^{\circ} 16.802\right)\end{array}$ & 2 \\
\hline $\begin{array}{l}\text { Principal tipo de } \\
\text { investimento }\end{array}$ & Público e privado & Predomínio público & 2 \\
\hline $\begin{array}{l}\text { Nível de abrangência } \\
\text { territorial }\end{array}$ & Nacional & $\begin{array}{l}\text { Mais restrito às grandes } \\
\text { cidades }\end{array}$ & 2 \\
\hline $\begin{array}{l}\text { Existência de instituições, } \\
\text { projetos e empresas de apoio }\end{array}$ & Quase a totalidade & Mais limitado & 3 \\
\hline $\begin{array}{l}\text { Grau do impacto tecnológico } \\
\text { para sua implementação }\end{array}$ & Alto & Incremental & 4 \\
\hline $\begin{array}{l}\text { Grau de criação de novos } \\
\text { modelos de negócios }\end{array}$ & $\begin{array}{l}\text { Elevado } \\
\text { (ex: carsharing, produção } \\
\text { de baterias, etc) }\end{array}$ & Mais limitado & 4 \\
\hline $\begin{array}{l}\text { Grau de geração de novos } \\
\text { empregos }\end{array}$ & $\begin{array}{l}\text { Elevado } \\
\text { (nova cadeia produtiva) }\end{array}$ & Mais limitado & 4 \\
\hline Regulamentação do setor & Em discussão & Existente & 4 \\
\hline
\end{tabular}

Fonte: Autores.

Se o objetivo da eletromobilidade no país tivesse apenas motivação de sustentabilidade ambiental (emissão zero de $\mathrm{CO}_{2}$ e redução de ruídos) ou de eficiência energética, o foco dessas ações enfatizaria o modal de transportes coletivos, nos centros urbanos.

Entretanto, percebe-se um predomínio de ações e atividades públicas e privadas voltadas para o desenvolvimento da eletromobilidade com foco no modal rodoviário (transporte individual) no país. Talvez, as possibilidades de novos negócios, novas ofertas de empregos e pesquisas justifiquem esta escolha.

Porém, se tais medidas irão, por um lado, estimular a produção e o consumo de mais veículos (VEs), por outro, vão aumentar ainda mais o tráfego nas vias urbanas no país. Ou seja, mesmo que possa significar um avanço na questão da sustentabilidade não contribuirão significativamente para o bem-estar social.

Desta forma faz-se necessário um direcionamento do que o Brasil quer com a eletromobilidade. Sem esta definição é difícil criar políticas públicas que mobilizem as instituições, alinhando os recursos e os projetos do ponto de vista da sustentabilidade e do bem-estar social. 


\section{REFERÊNCIAS}

[1] BRASIL. Ministério das Cidades. Política Nacional de Mobilidade Urbana. Brasília: MCidades, 2013. 37 p. 37 Disponível $<$ http://www.portalfederativo.gov.br/noticias/destaques/municipios-devem-implantar-planoslocais-de-mobilidade-urbana/CartilhaLei12587site.pdf $>$. Acesso em: 11 abril 2018.

[2] ASSOCIAÇÃO NACIONAL DOS FABRICANTES DE VEÍCULOS AUTOMOTORES. Anuário da indústria automobilística brasileira, São Paulo, 2018. Disponível em: $<$ http://www.anfavea.com.br/anuario.html >. Acesso em: 02 mar. 2018.

[3] ERNST \& YOUNG, "Guia de Mobilidade Corporativa". 2016. Disponível em: $<$ http://www.ey.com/Publication/vwLUAssets/Guia_de_Mobilidade_Urbana/\$FILE/Guia_de mobilidade_urbana_0909_v2.pdf $>$. Acesso em: 02 mar. 2018.

[4] MARTINNS, C. $\bar{N}$. Condicionantes da difusão do carro elétrico no Brasil: análise dos fatores institucionais, econômicos e técnicos. 2015. 224 f. Tese (Doutorado em Políticas Públicas, Estratégias e Desenvolvimento do Instituto de Economia, Universidade Federal do Rio de Janeiro, Rio de Janeiro, 2015. Disponível em: <http://www.ie.ufrj.br/images/posgraducao/pped/dissertacoes_e_teses/PPED_Tese_Claudia_Martins_Maro_de_2015.pdf $>$.

Acesso em: 02 mar. 2018.

[5] INTERNATIONAL ENERGY AGENCY - IEA. $\mathrm{CO}_{2}$ Emissions fuel Combustion Highlights (2017 Edition). Disponível em: $<$ https://webstore.iea.org/co2-emissions-from-fuelcombustion-highlights-2017>. Acesso em: 02 mar. 2018.

[6] BRASIL. Ministério de Minas e Energia. Balanço Energético Nacional 2017. Dados referentes a 2016. Brasília: MNE. 2017. 296 p. Disponível em: $<$ https://ben.epe.gov.br/downloads/Relatorio_Final_BEN_2017.pdf $>$. Acesso em: 02 mar. 2018.

[7] MCHUGH, D. Os planos para proibir carros diesel e a gasolina na Europa são realistas? A.gosto 2017. Disponível em: <http://www1.folha.uol.com.br/mercado/2017/08/1907190-osplanos-para-proibir-carros-diesel-e-a-gasolina-na-europa-sao-realistas.shtml $>$. Acesso em: 05 mar. 2018.

[8] AFP. Voiture électrique: Tavares demande aux Etats des infrastructures. Abril. 2018. Disponível em: <https://www.challenges.fr/economie/voiture-electrique-tavares-demandeaux-etats-des-infrastructures_571894>. Acesso em: 05 mar. 2018.

[9] PROMOB-e. O que é eletromobilidade? Disponível em: $<$ http://www.promobe.com.br/institucional/o-que-e-mobilidade-eletrica/>. Acesso em: 02 mar. 2018.

[10] SCHERF, C.; WOLTER, F. Eletromobilidade: Visão Geral, Exemplos, Abordagens. Transporte Urbano Sustentável, Documento Técnico \#15. Deutsche Gesellschaft für Internationale Zusammenarbeit (GIZ), maio 2016. Disponível em: $<$ http://www.sutp.org/files/contents/documents/resources/B_Technical-

Documents/GIZ_SUTP_TD13_Urban-Mobility-Plans_PT.pdf $>$. Acesso em: 02 mar. 2018. [11] FUNDAÇÃ̃ GETÚLIO VARGAS. "Carros Elétricos". Cadernos FGV Energia, Maio 2017, Ano 4. n. 7. Disponível em: <http://fgvenergia.fgv.br/>. Acesso em: 02 mar. 2018.

[12] TECNOLOGIA. Venda de carros elétricos cresce 58,9\% em 2018 mas revela limitação tecnológica. Abril 2018. Disponível em: <http://tecnologia.ig.com.br/2018-04-17/carroseletricos-brasil.html>. Acesso em: 02 mar. 2018.

[13] DEUTSCHE WELLE. Frota mundial de carros eletrificados cresce 55\% em um ano. Fevereiro 2018. Disponível em: $<$ https://g1.globo.com/carros/noticia/frota-mundial-de-carroseletricos-cresce-55-em-um-ano.ghtml>. Acesso em: 07 mar. 2018. 
[14] SILVA, C. O Estado de S.Paulo. Até 2030, carros a energia devem ser $10 \%$ da frota global. Setembro 2017. Disponível em: <http://economia.estadao.com.br/noticias/geral,ate2030-carros-a-energia-devem-ser-10-da-frota-global,70002009753>. Acesso em: 05 mar. 2018.

[15] TORREGROSSA, M. Véhicules électriques: immatriculations Europe et monde au $1^{\text {er }}$ trimestre 2018. Automobile Propre. $1^{\mathrm{o}}$ de maio de 2018. Disponível em: $<$ http://www.automobile-propre.com/vehicules-electriques-immatriculations-europe-etmonde-au-1er-trimestre-2018/>. Acesso em: 03 mai. 2018.

[16] EV SALES. Global Top 10 Mach 2018. 30 abril 2018. Disponível em: <http://evsales.blogspot.com.br/2018/04/global-top-10-march-2018.html>. Acesso em: 03 mai. 2018.

[17] BECK, R. Mobilidade Elétrica Padrões e Regulamentação no Brasil. Fórum BrasilAlemanha de Mobilidade Elétrica. São Paulo. Out. 2017. Disponível em: $<$ http://www.promobe.com.br/library/mobilidade-eletrica-padroes-e-regulamentacao-nobrasil/>. Acesso em: 02 mar. 2018.

[18] BRASIL. Ministério do Planejamento. PAC Mobilidade Urbana. Brasília: 2018. Disponível em: <http://www.pac.gov.br/infraestrutura-social-e-urbana/mobilidade-urbana>. Acesso em: 11 abril 2018.

[19] FINEP. Inova Energia. Disponível em: $<$ http://www.finep.gov.br/apoio-e-financiamentoexterna/programas-e-linhas/programas-inova/inova-energia $>$. Acesso em: 02 mar. 2018

[20] PASCOAL, E. et al. Sharing Economy and mobility: a future for electric vehicles and an opportunity for Brazilian automakers. SAE Technical Papers, 2017.

[21] BNDES Finem - Mobilidade urbana. Disponível em: $<$ http://www.bndes.gov.br/wps/portal/site/home/financiamento/produto/bndes-finemmobilidade-urbana>. Acesso em: 02 mar. 2018.

[22] BNDES Fundo Clima. Disponível $<$ http://www.bndes.gov.br/wps/portal/site/home/financiamento/produto/fundo-clima/fundoclima>. Acesso em: 02 mar. 2018.

[23] ZOMER, R. Eletromobilidade no Brasil Ontem, hoje e amanhã. Fórum Brasil-Alemanha de Mobilidade Elétrica. São Paulo. Out. 2017. Disponível em: $<$ http://www.promobe.com.br/wp-content/uploads/2017/11/Ricardo-Zomer-MDICF\%C3\%B3rum-Brasil-Alemanha-de-Mobilidade-El\%C3\%A9trica-19.10.2017.pdf $>$. Acesso em: 02 mar. 2018.

[24] Lei $\mathrm{n}^{\mathrm{o}}$ 16.802. Disponível em: <https://www.radarmunicipal.com.br/legislacao/lei16802>. Acesso em: 15 mar. 2018.

[25] SECRETARIA NACIONAL DE MOBILIDADE URBANA (SEMOB). Disponível em: $<$ http://www.cidades.gov.br/mobilidade-urbana>. Acesso em: 02 mar. 2018.

[26] AGÊNCIA NACIONAL DE ENERGIA ELÉTRICA - ANEEL. Mobilidade Elétrica. Disponível em: <http://www.aneel.gov.br/mobilidade-eletrica>. Acesso em: 02 mar. 2018.

[27] ITAIPU. Programa Veículo Elétrico Disponível em: $<$ https://www.itaipu.gov.br/tecnologia/veiculos-eletricos>. Acesso em: 02 mar. 2018.

[28] ITAIPU. Centro de Inovação em Mobilidade Elétrica Sustentável. Disponível em: $<$ http://jie.itaipu.gov.br/conte\%C3\%BAdo/itaipu-inaugura-centro-de-

inova $\% \mathrm{C} 3 \% \mathrm{~A} 7 \% \mathrm{C} 3 \% \mathrm{~A} 30-\mathrm{em}-\mathrm{mobilidade}-\mathrm{el} \% \mathrm{C} 3 \% \mathrm{~A} 9$ trica-sustent $\% \mathrm{C} 3 \% \mathrm{~A} 1$ vel-ci-mesnesta-quarta>. Acesso em: 02 mar. 2018.

[29] GRUPO DE ESTUDOS DO SETOR ELÉTRICO - GESEL. Disponível em: $<$ http://www.gesel.ie.ufrj.br/>. Acesso em: 02 mar. 2018.

[30] GRUPO DE ESTUDOS DE VEÍCULOS ELÉTRICOS - GRUVE. Disponível em: $<$ http://www.gruve.eng.uerj.br/>. Acesso em: 02 mar. 2018. 
[31] ASSOCIAÇÃO BRASILEIRA DO VEÍCULO ELÉTRICO - ABVE. Disponível em: $<$ http://www.abve.org.br/>. Acesso em: 02 mar. 2018.

[32] INSTITUTO NACIONAL DE EFICIÊNCIA ENERGÉTICA - INEE. Disponível em: $<$ http://www.inee.org.br/>. Acesso em: 02 mar. 2018.

[33] SERTTEL. Disponível em: <http://www.serttel.com.br/>. Acesso em: 02 mar. 2018

[34] HITECH ELECTRIC. Disponível em: <http://hitech-e.com.br/>. Acesso em: 02 mar. 2018.

[35] ELETRA. Disponível em: <http://www.eletrabus.com.br/>. Acesso em: 02 mar. 2018

[36] BYD. Disponível em: <https://www.facebook.com/BYDBrasil/>. Acesso em: 02 mar. 2018.

[37]

RENAULT-NISSAN.

Disponível

em:

$<$ http://www.imprensa.renault.com.br/pagina/busca_categoria/carros-eletricos/pt $>$. Acesso em: 02 mar. 2018.

[38] ENEL. Centro de pesquisa em mobilidade elétrica. Disponível em: $<$ https://www.enel.com.br/pr/historias/a201705-novo-centro-de-pesquisa-vai-estudarmobilidade-eltrica.html>. Acesso em: 02 mar. 2018.

[39] CPFL. Emotive. Disponível em: <https://www.cpfl.com.br/sites/mobilidadeeletrica/emotive/Paginas/default.aspx\#projeto>. Acesso em: 02 mar. 2018.

[40] PROMOB-e. Quem somos. Disponível em: $<$ http://www.promobe.com.br/institucional/quem-somos/>. Acesso em: 02 mar. 2018.

[41] AGÊNCIA NACIONAL DE ENERGIA ELÉTRICA - ANEEL. Programa de Pesquisa e Desenvolvimento Tecnológico do Setor de Energia Elétrica. Disponível em: $<$ http://www.aneel.gov.br/programa-de-p-d >. Acesso em: 02 mar. 2018.

[42] VEÍCULOS ALTERNATIVOS PARA MOBILIDADE - VAMO. Disponível em: $<$ http://www.vamofortaleza.com/>. Acesso em: 02 mar. 2018.

[43] PORTO LEVE. Disponível em: <http://www.portoleve.org/>. Acesso em: 02 mar. 2018.

[44] ECOELETRICO. Disponível em: <http://www.ecoeletrico.curitiba.pr.gov.br/>. Acesso em: 02 mar. 2018.

[45] NISSAN. Projeto Piloto de Táxi Elétrico de SP. Disponível em: $<$ http://nissannews.com/pt/nissan/brasil/releases/projeto-piloto-de-taxi-el-trico-de-sp-faseii?mode $=$ print $>$. Acesso em: 02 mar. 2018.

[46] NISSAN. Programa de Táxis Elétricos da Nissan no Rio completa dois anos evitando emissões de $\mathrm{CO} 2$ na atmosfera. Disponível em: $<$ http://nissannews.com/pt/nissan/brasil/releases/programa-de-t-xis-el-tricos-da-nissan-no-riocompleta-dois-anos-evitando-emiss-es-de-co2-na-atmosfera>. Acesso em: 02 mar. 2018.

[47] LEVE - Laboratório de Estudos do Veículo Elétrico. Disponível em: $<$ http://portal.ige.unicamp.br/pt-br/pesquisa/grupos-de-pesquisa/leve-laborat\%C3\%B3rio-deestudos-do-ve\%C3\%ADculo-el\%C3\%A9trico>. Acesso em: 09 mar. 2018.

[48] UNB. Laboratório de Veículos Elétricos. Disponível em: <https://fga.unb.br/unbgama/noticias/projeto-da-unb-desenvolve-pesquisas-com-motores-eletricos $>$. Acesso em: 09 mar. 2018.

[49] SAE Brasil. Comissão Veículos Elétricos \& Híbridos. Disponível em: $<$ http://portal.saebrasil.org.br/a-instituicao/comissoes-tecnicas/comissao-veiculos-eletricos-ehibridos>. Acesso em: 09 mar. 2018.

[50] UNIVERSIDADE FEDERAL DE SANTA CATARINA - UFSC. Ônibus Elétrico. Disponível em: <http://fotovoltaica.ufsc.br/sistemas/fotov/blog/2017/04/24/onibus-eletrico/>. Acesso em: 09 mar. 2018. 
[51] UNIVERSIDADE DE SÃO PAULO - USP. Escola de Engenharia de São Carlos. Disponível em: <https://jornal.usp.br/universidade/extensao/carro-eletrico-da-usp-em-saocarlos-pode-cruzar-o-pais-com-r-5/>. Acesso em: 09 mar. 2018.

[52] UNIVERSIDADE FEDERAL DO RIO GRANDE DO SUL - UFRGS. UFRGS deve ter serviço de aluguel de carros elétricos. Disponível em: $<$ https://www.ufrgs.br/empreendedorismo/?p=145>. Acesso em: 09 mar. 2018.

[53] MOBILAB. Disponível em: <http://mobilab.prefeitura.sp.gov.br/>. Acesso em: 08 mar. 2018 .

[54] MASSAKITI, M. Programa VE de ITAIPU - Visão Geral. Fórum Brasil-Alemanha de Mobilidade Elétrica. São Paulo. Out. 2017. Disponível em: $<$ http://www.promobe.com.br/library/programa-ve-de-itaipu-visao-geral/>. Acesso em: 02 mar. 2018.

[55] AGÊNCIA NACIONAL DE ENERGIA ELÉTRICA - ANEEL. Manual do Programa de Pesquisa e Desenvolvimento Tecnológico do Setor de Energia Elétrica. 2012. Disponível em: $<\mathrm{http}$ ://www2.aneel.gov.br/arquivos/pdf/Manual-PeD_REN-504-2012.pdf $>$. Acesso em: 02 mar. 2018.

[56] Mobilidade Elétrica. Relatório Técnico, UFRJ. 2014. Disponível em: $<$ http://www.provedor.nuca.ie.ufrj.br/estudos/reltec4.pdf>. Acesso em: 14 mar. 2018.

[57] SOARES, J. B. Eletromobilidade no Brasil: Perspectivas. Fórum Brasil-Alemanha de Mobilidade Elétrica. São Paulo. Out. 2017. Disponível em: $<$ http://www.promobe.com.br/library/eletromobilidade-no-brasil-perspectivas/>. Acesso em: 02 mar. 2018.

[58] BARAN, R., LEGEY, L. F. L. Veículos elétricos: história e perspectivas no Brasil. BNDES Setorial 33, p. 207-224. 2011. Disponível em: $<$ https://www.bndes.gov.br/SiteBNDES/bndes/bndes_pt/Galerias/Convivencia/Publicacoes/C onsulta_Expressa/Setor/Complexo_Automotivo/201103_06.html>. Acesso em: 02 mar. 2018. [59] BAZUCHI, K. Possibilidades de financiamento e internacionalização de projetos de Veículos Elétricos. Fórum Brasil-Alemanha de Mobilidade Elétrica. São Paulo. Out. 2017. Disponível em: $<$ http://www.promobe.com.br/library/possibilidades-de-financiamento-einternacionalizacao-de-projetos-de-veiculos-eletricos/>. Acesso em: 02 mar. 2018.

[60] CASTRO, B. Possibilidades de financiamento a Veículos Elétricos e Insights para Políticas Públicas no Brasil. Fórum Brasil-Alemanha de Mobilidade Elétrica. São Paulo. Out. 2017. Disponível em: <http://www.promobe.com.br/wp-content/uploads/2017/11/BernardoCastro-BNDES-F\%C3\%B3rum-Brasil-Alemanha-de-Mobilidade-El\%C3\%A9trica20.10.2017.pdf/>. Acesso em: 02 mar. 2018.

[61] CONSONI, F. Políticas públicas e governança na instalação e disseminação da infraestrutura de recarga: modelos e experiências. Unicamp. 2017. Disponível em: $<$ http://www.aneel.gov.br/documents/10184/15266087/Pol\%C3\%ADticas+p\%C3\%BAblicas $+\mathrm{e}+$ governan $\% \mathrm{C} 3 \% \mathrm{~A} 7 \mathrm{a}+$ na + instala $\% \mathrm{C} 3 \% \mathrm{~A} 7 \% \mathrm{C} 3 \% \mathrm{~A} 3 \mathrm{o}+\mathrm{e}+$ dissemina $\% \mathrm{C} 3 \% \mathrm{~A} 7 \% \mathrm{C} 3 \% \mathrm{~A} 3 \mathrm{o}$ $+\mathrm{da}+$ infraestrutura $+-+\mathrm{Fl} \% \mathrm{C} 3 \% \mathrm{~A} 1 \mathrm{via}+\mathrm{Consoni.pdf} / \mathrm{c} 38 \mathrm{f} 2 \mathrm{e} 4 \mathrm{e}-1 \mathrm{~d} 2 \mathrm{e}-16 \mathrm{e} 7-\mathrm{a} 930$ a7721cce5bb6>. Acesso em: 01 mar. 2018. 